\title{
Preschoolers' Moral Actions and Emotions in Prisoner's Dilemma
}

\author{
David Matsumoto, Norma Haan, Gary Yabrove, Paola Theodorou, and Caroline Cooke Carney \\ Institute of Human Development, University of California, Berkeley
}

\begin{abstract}
The moral acts of 19 dyads of 4-year-olds in a cognitively simplified version of Prisoner's Dilemma were analyzed in relationship to their friendship, emotions, and processes of conflict resolution. Degree of friendship was rated by teachers; two sociologists used a Q-sort of Group Processes to describe the dyads' interactions; the emotions of each child were coded from videotape-independently of his or her partner's and with the sound turned off-in accordance with Ekman and Friesen's (1983) Emotion Facial Action Coding System. Moral acts were categorically identified as equalization, reparation, stalemate, default, and betrayal; these acts were also assigned scale scores on a dimension of moral sensitivity that was independently derived from separate work with a sample of 143 undergraduates. They judged the five acts in all possible paired comparisons and then rated the moral difference between each pair. These data almost perfectly fitted a model of increasing monotonic function according to Kruskal's (1964) criterion. The degree of friendship between the dyads and their interactive processes-group orientation, positive emotional tone, and active involvement-were positively related to sensitive moral action. Their emotions were related to concurrent acts, and more importantly, predicted their subsequent acts even though they seldom talked about morality. These results suggest that if social scientists' search for practical morality is to be successful, emotional communication needs to be brought into the account.
\end{abstract}

A substantial and still growing number of investigations (for a few of the many examples, see Main \& George, 1985; Rheingold \& Hay, 1980, Strayer, 1980; and an extensive review by Radke-Yarrow, Zahn-Waxler, \& Chapman, 1983) suggest that young children may be neither as morally insensitive nor incapable as held in theories that define morality and its development as primarily due to cognitive development or socialization. These contrary findings especially seem to occur in investigations that concern young children's moral actions rather than their judgments about hypothetical dilemmas. Still those cognitive scientists (for instance, Anderson, 1980) who have taken special care in simplifying and clarifying the cognitive requirements of their tasks also report such findings. Thus this growing body of work raises questions about the nature of young children's morality. Here we are concerned only with the conditions of their action, which is surely the more convincing test of moral capability. An obvious but not frequently studied feature of moral action is its heat-its "hot cognitions" in contrast to the cool cognitions evoked by hypothetical problems

This researchrwas supported by a grant from the National Institute of Mental Health, RO1 MH37290, to Norma Haan, Principal Investigator, who was also supported by a Research Scientist Award, KO5 MH00258-07. David Matsumoto was supported by a minority fellowship from the American Psychological Association, under Clinical Training Grant 5 T01 MH13833 from the National Institute of Mental Health.

We are grateful for the assistance of Barbara Scales, Kay McElheney, and Jane Hunt of the Child Study Center, Institute of Human Development. We appreciate the care Joseph Hager gave to the emotion coding. Consultation with Paul Ekman and Linda Camras was most helpful.

Correspondence concerning this article should be addressed to David Matsumoto, The Wright Institute, 2728 Durant Avenue, Berkeley, California 94704 .
(Cofer, 1981; Siegal \& Francis, 1982). Because acts of moral consequence are usually conflictual, emotion is involved.

We report a study of 4-year-olds' moral actions in a famous situation-Prisoner's Dilemma, which has not always been explicitly identified as morally conflictual. (But see Axelrod, 1984; Dawes, Orbell, \& Van de Kraft, 1985; and Rapoport \& Chammah, 1965, for an extensive description of Prisoner's Dilemma.) Dawes and his associates (1985) have shown in a lengthy series of experiments with Prisoner's Dilemma that altruistic solutions occur, even when incentives in the situation are compatible with self-interest. This "game" can be recognized as paradigmatically moral because partners' fates are entirely coordinate: Neither can "win" against a sensate partner on the conventional basis of fair competition or luck; instead single-minded pursuit of self-interest becomes a default; when both partners default, stalemate results and conflict escalates. Partners' only viable and morally sensible solution is to take less than their initially held view of their self-interests suggest. The interdependency of partners' interchange during Prisoner's Dilemma illustrates John Donne's classical warning that no man is an island, a lesson that continuously confronts preschoolers in the give and take of their play.

Morally sensitive acts of young children cannot be readily attributed to their cognitive ability to draw conclusions from moral principles or to their lengthy socialization; thus the possibility comes to mind that emotions may convey immediate, authentic understandings of protagonists' basic reactions to equity and inequity, perhaps more persuasively than words allow. This thought extends Zajonc's (1980) contention that "emotion needs no inference" to suggest that evaluation of another person's basic reaction to inequity or equity from his or her emotional expressions may not require extensive inference. (Evidently this is not a complex capability, because recent work 
[Axelrod \& Hamilton, 1981; Lombardo, 1985] suggests lower species act reciprocally following apparent affective displays, whether or not they are genetically related.) Which emotions occur during moral conflict and how they may influence moral actions has not been extensively studied. Yet protagonists' nonverbal emotional interchanges during moral conflict may be influential, and their investigation may elucidate the dynamics of moral action in ways that exclusive focus on cognition or on appropriate conformity cannot.

Past experience that ensures a degree of mutual good faith is undoubtedly a necessary but insufficient condition of solid friendship among people of all ages. Consequently the extent of protagonists' friendship may serve as a backdrop for their moral interchange. Friends have ready-made moral expectancies of each other. They can usually disagree and correct each other's falsifications without jeopardy because they readily forgive one another. Friends also have a stake in their future relationship, so they may be especially motivated to reach stable resolution. The view that friendship facilitates moral exchange has considerable precedence in various studies, mostly of older children. Newcomb and Brady (1982) found greater prosociality among 7- and 12-year-old friends than among acquaintances. However, past study has not supported the view that friends are continuously harmonious (see Berndt, 1983; Gottman \& Parkhurst, 1980). Although Nelson and Aboud (1985) studied 9- and 10year-olds dealing with hypothetical issues of social knowledge, their findings are consistent with our expectancies about the function of friendship in moral conflict. They found that friends gave each other more explanations and criticisms than nonfriends and that disagreeing friends came to more morally mature solutions. Because young children are readily stressed, we reason that friendship may ameliorate their stress, thereby making it possible to work through the inevitable conflict of moral issues that require action.

Protagonists' prior relationship may specifically affect whether or not they set forth ideas, react to one another's feelings, and take account of their partner's as well as their own needs. Children who become apathetic or guarded in moral interactions would seem to have less chance of handling the conflict and may therefore end up violating either their own or the group's self-interests.

\section{Overview of the Present Study}

The present study is an exploratory probe into the conditions and processes of 4-year-olds' moral interchange. Pairs of children engaged in a version of Prisoner's Dilemma (NeoPd) which was morally demanding and conflictual, but cognitively simplified so as to diminish possibilities of confounding cognitive and moral levels. To avoid confusing the children's performance under duress with their moral potential, staff leaders encouraged the children's efforts to cope. Each child's videotaped emotional reactions were coded independently from his or her partner's with the sound turned off. Moral scores were obtained for each interim act and for each child's and the dyad's overall moral performance. The degree of each dyad's friendship was obtained from teachers' ratings and descriptions of the interactions during the task were provided by sociologists' Q-sort ratings.
We hypothesized: (a) The degree of the dyads' friendship and interactive processes would be associated, with pairs of better friends being more actively responsive to both self- and otherinterests. (b) Both the ratings of friendship and interactive processes would be associated with moral action, with energetically interacting good friends achieving higher moral scores. (c) Specific kinds of emotional reactions would be correlated with different kinds of moral acts. (d) Specific kinds of emotional expressions would predict the children's subsequent moral acts.

\section{Method}

\section{Preschoolers and Friendship}

Participating were 38 preschoolers, 22 from a university-run nursery school and 16 from a parent cooperative nursery school housed in the same building. Their ages ranged from 4 years, 2 months to 5 years, 3 months, with an average of 4 years, 6 months. Pairs were from the same school. There were eight male-male pairs, nine female-female pairs, and the two male-female pairs. The small $N$ precludes meaningful analyses of sex differences on all variables, which in any case were not significant when the dyads' moral scores (the average of the partner's individual scores) were compared using a Mann-Whitney $U$ test.

The degree of friendship for each pair of subjects was rated by their teachers on a 5-point scale, ranging from 1, indicating not friends at all, to 5 , indicating best friends. The one teacher in the cooperative nursery school made the friendship ratings, as did the three teachers for the university-run nursery school. Thus only single ratings were used for pairs from the cooperative school, but the average of the three teacher's ratings were used for the university school children; $82 \%$ of these ratings agreed completely or varied by only one step.

\section{The Situation and Its Simplification}

The usual play of Prisoner's Dilemma involves two people in a series of plays for payoffs, the amounts being determined by the coordination between their choices of blue or red cards. Players are usually given a printed, four-celled matrix showing the payoffs for each of four plays: stalemate (no payoffs), cooperation (moderate payoffs for both), or competitive outcomes (high payoffs for one person, losses for the other). However, the following changes for NeoPd were made to simplify the task cognitively, whereas the usual moral demands were not changed.

1. To make it easy for the children to check and recheck the consequences of different plays, a concrete and colorful board showing the pay-offs was placed before them (see Figure 1). This form was developed after extensive pilot work with preschoolers, which showed that they could not grasp the coordination of two-valued intersections even after careful explanation and actual play. Thus the serial presentation of payoffs shown in Figure 1 was adopted; it has the very same moral consequences as the four-cell matrix.

2. The children needed immediate and continuous information about consequences of the different coordinations, so pennies were paid off after each play, rather than at the end of the session. The children each had a bowl for their pennies so they could keep track of their own and their friends' earnings.

3. In pilot work, 4-year-olds became very upset when they lost pennies. Thus, the competitive outcome was changed so one child would receive two pennies while the other child simply received no pennies, instead of losing pennies.

4. To achieve greater ecological validity and provide a way to investigate processes, two children played with each other (rather than with an imaginary partner as is usual in social psychological studies involving Prisoner's Dilemma). The children were encouraged to speak and react to one another. 


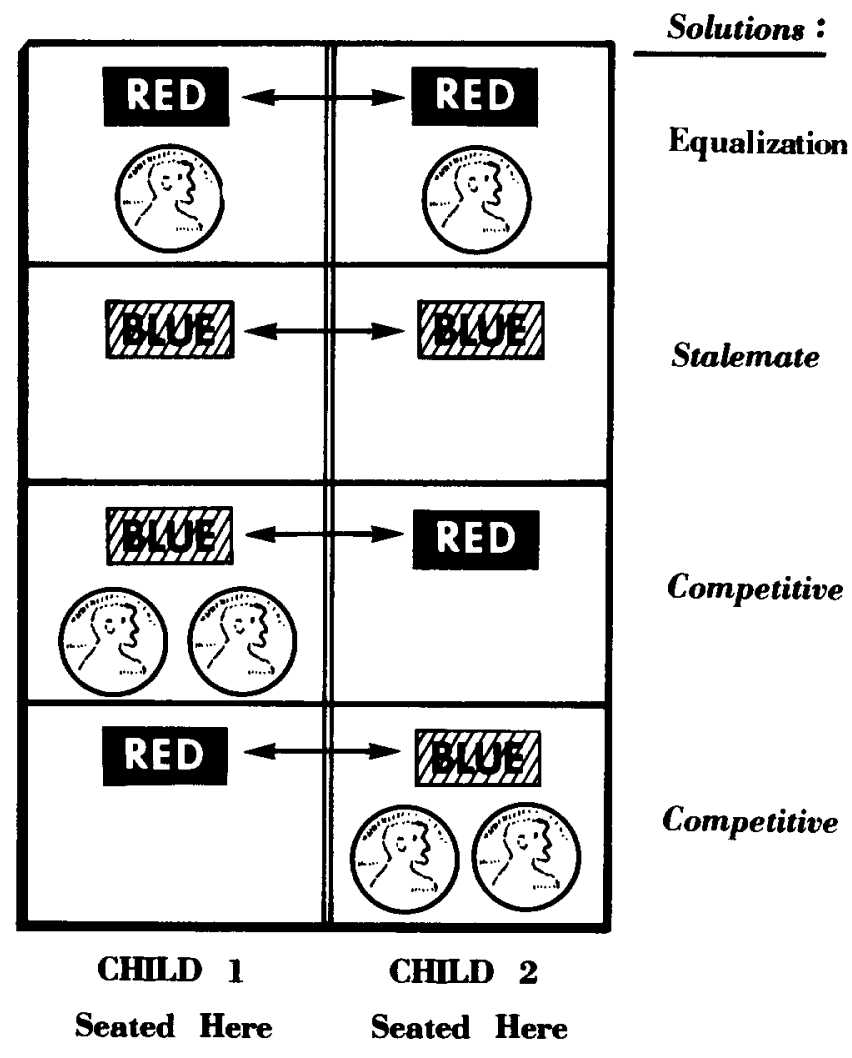

Figure 1. NeoPd board used with 4-year-olds.

\section{Procedure}

The children were invited by a staff leader, assisted by a teacher, to play a game in a room in the same building as their schoolroom. They were not required to participate but all did. This task was part of a larger project so this was the fourth time they had participated. Nevertheless, they were again shown the video equipment and told that they could watch themselves on TV after the game, which they seldom chose to do. They were seated side by side behind a table, and the staff leader placed strips of paper showing each child's name above his or her side of the board, shown in Figure 1. They were told that they could win pennies to take home. The staff leader then explained the task and engaged the children in several practice trials. Pilot work had also shown that actual experience with the pay-offs helped 4-year-olds fathom the consequences. When they seemed to understand, the real game began and pennies were awarded after each trial. Almost all sessions lasted for the approximate 20 minutes allowed by the school's regulations for the children's research time. (Two dyads who could not reach satisfactory solution chose to quit in about 15 minutes.) The entire session was videorecorded with video images including a face and trunk view of both interactants as they sat side by side.

Following techniques used by child therapists, the staff leaders took a facilitative but nondirective role. Pilot work had shown that 4-year-olds frequently broke off play when the adult acted remote or detached. Thus staff leaders encouraged the children to confront the issues, express their thoughts and feelings, and discuss game strategy, but the leaders did not act in ways that would persuade the children that one kind of behavior was better than another.

The leaders' comments were tallied for a randomly selected subsample of six dyads; a total of 438 comments were readily classified in four categories with the following incidences: (a) $28 \%$-clarifying the conse- quences of play, for example, "Look at the board. If you both play blue, nobody gets any pennies." (b) 54\% - facilitating interaction, for example, "Jimmy, did you hear what Johnny said? He's going to play red. Do you two want to talk about that?" (c) 15\%-directing schedule of play, for example, "Ready to play, 1, 2, 3, choose." (d) 3\%-maintaining focus on the task, for example, "Please sit down, Johnny." The staff leader made comments in this last category for only two of the six dyads included in this classification.

\section{Data}

Codes for moral acts. Five different acts can occur in this version of Prisoner's Dilemma. Equalization gives equal and moderate benefits to both. Default occurs when one person attempts to score heavily while the other attempts to equalize. Stalemate occurs with no payoff for either partner when both try to score heavily. Because participants can negotiate with one another in NeoPd-a necessary provision if the situation is to model everyday moral interchange-two more actions are readily identified: Betrayal occurs when one person explicitly promises to equalize but then unexpectedly plays blue (with payoff), thereby defaulting on his or her partner who trustingly plays the equalizing red card. Reparations occur when the partner who is ahead in pennies offers or agrees to play the red (thereby receiving no pennies) and the person behind puts down blue "to catch up" in total number of coins.

A single coder classified all plays for each pair into one of these five categories. Reliability coding was independently done by a second person on a random sampling of $15 \%$ of all plays. Their agreement was .90 .

A dimension of overall moral sensitivity. On the basis of ordinary judgment, equalization and reparations seemed "more moral" to us than default and betrayal; stalemate seemed intermediary. Consequently we thought these acts could possibly be scaled on a dimension of increasing moral sensitivity, a procedure that would yield two advantages. Judgments for scaling the differential moral adequacy of these acts would be independent of our personal opinions, and the scale scores would allow scores of overall moral performance for the entire session to be calculated. Thus two samples of students (total $N=143$ ), one from a commuter university and the other from the University of California, were recruited to judge all possible pairings of the different acts, which were described in nonpejorative, ordinary words, for example, "taking-in" for betrayal. They were instructed to rely on their own common sense definition of morality. After choosing the more moral act in each pair, the undergraduates rated their moral difference on an 11point scale; 0 represented no difference, 5 a moderate difference, and 10 a large difference.

The pairs of acts were presented in two different orders and equally counterbalanced between the respondents. Mean judgments for each pair of acts for each order were computed, entered into a matrix, and then plotted to check the fit of the difference models for each order. Because the data for the two orders both met graphical criteria for parallelism and unidimensionality, they were averaged and submitted to the ALSCAL procedure to obtain scale values for each act. Equalization and reparations had the highest and almost identical scale values (indicating greater degree of moral sensitivity), and acts of betrayal and default received the lowest scale values. The observed rank order of judgments modeled an increasing monotonic function almost perfectly (.4\% error) according to Kruskal's (1964) criterion. Thus scale values were assigned to each act for each child, and the dyads' scale scores for the entire session were computed by averaging both partners' scale scores for all their acts.

The Q-sort of group processes. To describe the interactive processes of each dyad, a 20-item Q-sort was independently completed for each dyad by two sociologists after they viewed the videotape. Four items were sorted on each step of a 5-point scale. The $Q$ agreement between their sorts did not agree at the criterion of .50 for nine dyads so a third sorter repeated the procedure. The two sorts of highest $Q$ agreement 
across the 20 items were eventually composited and used; the average reliability of these composites was .84 with a range from .67 to .97 . These data provide meaningful descriptions of the children's processes of moral resolution, but they are not independent of other dataalthough the sociologists were blind as to other scores and naive about the hypotheses of this study.

Because the 20 items were intercorrelated and too numerous, they were aggregated in five intercorrelated groups to obtain scores for each dyad. The five clusters with an exempler item follow: (a) group-oriented functioning: Children try to persuade each other on the basis of group needs; (b) self-initiated problem solving: Children take initiative in providing solutions; (c) positive emotional tone: Children seem satisfied at end; (d) hyperactive dominance: Clear acts of domination occur; and (e) active involvement: Both partners participate.

Coding of emotional reactions. The children's emotional expressions were coded using Ekman and Friesen's (1983) Emotion Facial Action Coding System (EMFACS), which is an abbreviated version of Ekman and Friesen's (1978) more extensive Facial Action Coding System (FACS). Whereas the latter provides an anatomically based comprehensive description of all possible facial muscle movements, EMFACS is more economical. It achieves this economy: (a) by focusing only on those muscle movements that are theoretically or experimentally related to emotion expression; (b) by marking only a single point in time when the facial behavior occurred, rather than laboriously marking the onset, apex, and offset of the movement; and (c) by focusing the coder on real time only, rather than the repeated, slow motion viewing often required for FACS coding.

EMFACS detects partial and full expressions for the six "basic" emotions (anger, disgust, fear, happy, sad, surprise), as well as blends of two or more emotions (cf. Ekman \& Friesen, 1975). EMFACs also differentiates two general types of smiling expressions, based on the presence or absence of a tightening of the muscle around the eye (orbicularis oculi). In felt smiles the smiling muscle (zygomatic major) is innervated in conjunction with the muscle around the eye; in unfelt smiles, only the smiling muscle is innervated. The theoretical differences among various types of smiles have been discussed elsewhere (see Ekman \& Friesen, 1982).

For emotional coding, one 45-s video segment was selected for each kind of moral act (if they had occurred) for all pairs. This procedure produced 17 acts for equalization, 8 for reparation, 13 for stalemate, 13 for default, and 10 for betrayal. The criterion for the selection of each of these acts was their first occurrence after staff persons judged that both partners understood the coordinated consequences of their play.

A rater with extensive experience with EMFACS, who was blind to the situations, the identity of the depicted acts, and the hypotheses, coded one child's emotional expressions with the view of the other child covered. Coding was completed first for all children on the right- and then on the left-hand side of the screen. The staff leader was not in view, and the audio was turned off so emotion coding could not be influenced by verbal statements. To determine reliability, a second independent rater coded $25 \%$ of the total sample. Reliability was .79, which is acceptable according to guidelines established by Ekman and Friesen (1978).

\section{Results}

Results are based on friendship ratings, emotion codes, scores for dyadic processes, and moral action, but only the friendship ratings have an independent source. Because the emotion codes, group processes, and moral scores are based on the same situation, their function is the explication of the conditions and processes of moral resolution within NeoPd. To reduce redundancy, these different data sets were independently generated by different sets of people with differing expertise, information, and intent. Because the number of pairs $(N=19)$
Table 1

Incidence of Different Actions Within Different

Periods of the Session

\begin{tabular}{lrrr}
\hline & \multicolumn{3}{c}{ Periods within session (\%) } \\
\cline { 2 - 4 } & I & II & III \\
\hline Moral Solutions & & & \\
$\quad$ Equalizations & 28 & 34 & 53 \\
$\quad$ Reparations & 14 & 6 & 4 \\
$\quad$ Total & 42 & 40 & 56 \\
Stalemate & 28 & 35 & 25 \\
Moral Violations & & & \\
$\quad$ Default & 29 & 17 & 12 \\
Betrayal & 2 & 8 & 7 \\
$\quad$ Total & 31 & 25 & 19 \\
\hline
\end{tabular}

was small and the emotion data was entirely categorical, use of refined methods that allow control for one condition as another is examined was not proper.

\section{Incidences for Different Moral Acts}

To establish the preschoolers' basic moral sensitivity, we first report the incidences for the preschoolers' violations (stalemate, betrayal, and default) and moral solutions (equalization, reparation). Computation for the entire session of the total percentages for each type of moral act showed that the preschoolers did equalize $(38 \%)$ and make reparations $(8 \%)$ with each other. They also defaulted $(20 \%)$, betrayed $(5 \%)$, and stalemated $(30 \%)$. An approximate frame of reference for these incidences is provided by two previous studies that used a similar version of NeoPd but with friendship groups of 8 or 12 members (Haan, 1978, in press; Haan, Aerts, \& Cooper, 1985). The preschoolers had higher incidences of both equalization and default (32\% and $21 \%$ ) than adolescents ( $9 \%$ and $10 \%$ ) who more frequently stalemated (64\%); the children had about the same incidence of equalization but more defaults (32\% and $21 \%$ ) than young adults (29\% and $12 \%)$.

The preschoolers' comparably favorable incidence of equalization suggests their interest in reconciliation. But their higher incidence of default signals their self-servingness, which alternatively might represent their difficulties in sustaining themselves in the midst of conflict. Whatever the case, they profited from experience. Table 1 shows the incidences for their five different acts during the early, middle, and late segments of the sessions. Their equalizations steadily increased while their defaults decreased.

\section{Friendship and Group Processes}

Pearson product-moment correlations were computed between the 19 dyads' friendship ratings and scores for group processes: Friendship ratings were significantly correlated with three of the five scores for group processes: active involvement $(r=.65 ; p \leq .001)$, positive emotional tone $(r=.31, p \leq .10)$, and group oriented functioning $(r=.38, p \leq .05)$. Thus pairs who were better friends worked for mutual rather than self-in- 
Table 2

Correlations Between Dimensions of Group Process and Percentage of Moral Solutions

\begin{tabular}{|c|c|c|c|c|c|}
\hline Moral actions & $\begin{array}{l}\text { Group-oriented } \\
\text { functioning }\end{array}$ & $\begin{array}{c}\text { Problem } \\
\text { solving }\end{array}$ & $\begin{array}{c}\text { Positive } \\
\text { emotional tone }\end{array}$ & $\begin{array}{l}\text { Hyperactive } \\
\text { dominance }\end{array}$ & $\begin{array}{c}\text { Active } \\
\text { involvement }\end{array}$ \\
\hline Equalizations & $.73^{* * * *}$ & $.44^{*}$ & $.63^{m * *}$ & -.18 & -.29 \\
\hline Stalemate & $-.62^{* * *}$ & $-.45^{*}$ & $-.50^{* *}$ & .35 & -.02 \\
\hline Default & $-.60^{* * * *}$ & $-.52^{* *}$ & .24 & .03 & $-.67^{* * * * *}$ \\
\hline Betrayal & -.25 & -.03 & $-.58^{* * *}$ & -.07 & -.02 \\
\hline \multicolumn{6}{|l|}{ Total scale } \\
\hline
\end{tabular}

${ }^{*} p \leq .05 .{ }^{* *} p \leq .01 .^{* * *} p \leq .005 .{ }^{* * * *} p \leq .001$.

terests; they were more engaged in the interaction and generally more relaxed and satisfied during the sessions. Strong friendship between children seemed then to provide a setting that allowed the children to be active, comfortable, and optimistic as they worked through the conflict. All the significant productmoment correlations reported in this section and below survived when they were recalculated using Spearman rank-order rho's and Kendall tau's; thus significance levels were not artifacts due to distribution of ratings.

\section{Moral Acts and Degree of Friendship}

Correlations were computed between the 19 pairs' friendship ratings and the overall percentages for the moral acts of equalization, stalemate, and default. (Calculations for reparations and betrayal are not reported because their low incidence resulted in skewed distributions.) Pairs of good friends equalized more $(r=.45, p \leq .05)$ and defaulted less $(r=-.46, p \leq .05)$, and they had higher scale scores for the entire session $(r=.47$, $p \leq .05$ ). Thus, good friends more frequently solved the conflict of NeoPd with moral sensitivity compared to dyads who were not as good friends.

\section{Moral Acts and Group Processes}

The associations of the dyads' five scores for group processes with the percentages for their five different moral acts and with their averaged scale scores are shown in Table 2 . The percentages for the moral acts are interdependent in the sense that more frequent equalizations mean fewer stalemates and/or defaults. Nonetheless, the essential thrust of these results is that greater moral sensitivity - more frequent equalization and higher scale scores-was associated with the sociologists' judgments that the dyads' functioning was more group oriented, problem-solving in orientation, and positive in emotional tone. Stalemating had negative associations with these same group processes, as did defaulting, although the latter was independent of emotional tone. In addition, substantial defaulting had a substantial negative relationship with active involvement, suggesting that uninvolved dyads more frequently took the simple solution of supporting their own self-interest.

\section{Verbal Articulation}

The findings given so far suggest that the dyads' friendship and their emotionally positive, mutual, and problem-solving in- terchanges had the expected, positive associations with their scores for moral action. Our "clinical" observations of the preschoolers' interactions suggested, however, that their actual articulation of moral ideas was so limited that their verbal exchange could not have persuaded them to act morally. Consequently the incidence of their moral verbalizations during the 61 excerpts selected for emotion scoring were coded. The criteria were either the explicit use of a moral word like "fair" or "should" or a sentence that expressed a moral idea like "you're not letting me win any pennies." Ten excerpts were double coded and because two independent coders had perfect agreement, no further checking was done. During $69 \%$ of the $61 \mathrm{seg}-$ ments, neither partner made a moral comment; during $24 \%$ one partner made a single comment, and during $7 \%$ both did. Because verbal persuasion was essentially not used, we were led to the possibility that the children's emotional reactions communicated persuasive moral outrage and satisfaction. Subsequent analyses then concerned whether the children's nonverbal emotional processes were related to specific types of moral acts and whether particular emotional reactions predicted subsequent acts.

\section{Moral Action and Emotions}

Were expressions of emotion evident in the interactions? The children displayed rich, varied affective repertoires; $96 \%$ showed some codable type of emotion, with most displaying two or three different emotions in the 45-s segments. However, four particular expressions were prevalent: felt smiles, unfelt smiles, negative expressions, and positive/negative expressions. The difference between felt and unfelt smiles was discussed above (cf. Ekman \& Friesen, 1982). Negative expressions include furrowed brows of anger and nose wrinkles of disgust and so forth (see Ekman \& Friesen, 1975). Positive/negative expressions contain simultaneous but contradictory (smiling and negative) elements. Ekman and Friesen (1982) suggest that the latter represent either attempts to mask negative feelings by smiling or mixtures of positive and negative emotion.

Were different moral actions accompanied by particular changes in emotional states? Changes in emotion from before to after each act were next analyzed. Data for the two acts of equalization and reparation were combined as moral solutions and betrayal and default as moral violations because of the small $N$. Change was evaluated using both a sign test and a Wil- 
coxon matched-pairs ranked-sign test; all findings were significant at $p \leq .05$ for both tests, except in one instance reported below.

Systematic relationships between emotions and acts occurred: Partners who reached moral solutions typically decreased in negative emotion $(p \leq .05)$, possibly indicating a reduction in tension or satisfaction over their mutual moral success. When the preschoolers violated their partners, either by betraying or defaulting, the violators' felt happiness increased $(p \leq .10)$, suggesting their satisfaction-however temporary it might be-about having protected their self-interests. But their unfortunate partners increased in both unfelt smiles $(p \leq .05)$ and positive/negative expressions $(p \leq .05)$. These increases may have reflected the victims' attempts "to save face" by masking or concealing their true feelings about being violated.

Did emotional reactions predict subsequent moral acts? This question is a critical one for moral theory because an affirmative answer (based on more studies than just this one) would suggest that emotion serves as a communication that influences moral action, at least in the very young. The first emotion shown by both partners after a play was cross tabulated with the moral acts of the next play.

When the children equalized they were likely to equalize again or make reparations in their next play when one or both children expressed felt happiness; but if they expressed an emotion other than felt happiness or expressed no emotion, they were then more likely to stalemate, default, or betray in the subsequent act, $\chi^{2}(1, N=17)=6.11, p \leq .05$. Thus moral solutions were more likely to be repeated when protagonists signaled satisfaction but less likely to be repeated when feedback was absent or negative.

We then analyzed the emotional reactions that followed violations with the hypothesis that the victims' reactions (rather than the victimizers') would predict the subsequent act. This expectancy is based on the common observation that violaters of all ages often act obliviously rather than immorally; thus the initiative for correction becomes the victims' who will then need to act in protection of their legitimate self-interest to set matters to right. When victims reacted with an unfelt smilesignaling a lack of forgiveness-the pair was most likely to move to the negative escalations of stalemating or violating on the next play; but when the victims reacted with felt smiles-thus not escalating the conflict, possibly because they did not regard the violation seriously or hoped their partner would still play in good faith-the pair either equalized or made reparations on the next play, $\chi^{2}(1, N=20)=4.74, p \leq .05$.

The number of reparations was small, but their pattern is equally suggestive. In the eight reparations, six were followed by the receivers expressing an unfelt smile-possibly signaling some discomfort with receiving charity-and in all six instances the receivers' next play was a stalemate or default. The remaining two reparations were followed by equalization after the receivers expressed felt happiness. As for stalemates, 10 out of the 13 were followed by equalization, with 9 of these being preceded by one or both partners expressing the ambivalence of unfelt smiles or the dissatisfaction of negative expressions.

\section{Discussion}

The results show that (a) these 4-year-olds were able to act morally in a cognitively simplified but morally conflictual situa- tion even though their self-interests were threatened; (b) they increasingly coordinated their actions across the sessions to achieve mutual moral solutions as they acquired experience with the consequences; (c) group orientation, active problemsolving, and positive feelings were associated with moral solution; (d) good friends were better able to resolve their difficulties and reach moral mutuality; (e) nonverbal emotional processes rather than verbal articulations were sensibly related to concurrent moral behaviors; and (d) emotional reactions predicted the 4-year-olds' future actions.

These findings are a function of a set of optimal circumstances that we suggest support ecologically credible moral action in the young: First, NeoPd was cognitively simplified to avoid confounding the preschoolers' cognitive deficiency with their moral capability. Second, NeoPd (as well as Prisoner's Dilemma) precipitates genuine moral conflict because participants have no satisfactory or "successful" solution to their difficulty other than reciprocal coordination. For this reason, NeoPd is a more stringent test of preschoolers' morality than are most spontaneous prosocial acts of giving away resources that in many instances are surplus and therefore trivial. Reasonable fulfillment of self-interest in NeoPd is legitimate, but selfinterest must be compromised and, as Rawls (1971) commented, to give away all resources is irrational. This complexity of interchange is not always represented in prosocial acts. Third, the staff leaders took a morally neutral role but supported the preschoolers' coping with this demanding, stressful situation with the intent of securing the children's best performance. Fourth, the children all knew each other but varied in the extent of their friendship, a circumstance we suggest affects good faith at least in early stages of moral interchanges. Fifth, the children seemed highly motivated to earn pennies and their particular emotional reactions to violation and equalization corroborated this observation. Sixth, moral assessments depended on actions, and not on the preschoolers' verbalizations about morality.

These findings have several limitations. The small sample size and its nonrepresentativeness limit their generalizability and made more complex analyses impossible, for example, controlling for friendship as the relationship between emotion and morality is examined. Also there were several technical restrictions. The quality of the video images may have prevented detection of small, quick expressions of emotion. Because the children sat side by side instead of facing each other, the opportunities for emotional communication may have been reduced. These technical limitations could be easily remedied in future work.

Given these cautions, the findings are still suggestive for future theory building and research. Morality has usually been regarded by philosophers, lay persons, and social scientists as a relatively complex phenomenon only acquired later in life and only after experiences that promote cognitive capability or socialized behavior. The present findings along with the growing number of studies reporting young children's moral sensitivity suggest that the basic impulse of practical morality may be simpler. Children, like adults, seem capable of a range of morally sensitive behaviors. As Radke-Yarrow et al. (1983) conclude after their review of some 400 studies, preschool children "are not only egocentric, selfish, and aggressive; they are also exquisitely 
perceptive, have attachments to a wide range of others, and respond prosocially across a broad spectrum of interpersonal events in a wide variety of ways and with various natures" ( $p$. 484). Given the possibility that preschoolers can act with moral sensitivity, incapacity is not a logical explanation for their frequent defaults or betrayals.

We offer a possible but speculative formulation. If the moral impulse is simple, it may be that morality only seems to become more complex because situations wherein the young are required to deal with morality grow more complex as do their capabilities of articulating and actually carrying out moral ideas. Understandably, small children have been regarded as morally deficient because they often act that way. Nevertheless to conclude on this basis that they lack moral sensitivity may confuse capacity with stressed performance. But to learn more about capacity, observations of optimal performance are necessary. Young children may often default because, objectively and subjectively, they are stress-vulnerable. Their inexperience means they often confront novel situational pressures; they lack knowledge as well as psychological and material resources; furthermore it is often sensible for them to capitulate because adult authority frequently decides the issues. Thus children are frequently helpless, and one kind of helplessness is moral outrage, which can eventually lead people of all ages to violate. In this light, moral development may not be so much the development of morality per se (as traditionally formulated) but rather the development of problem-solving capabilities that support more adequate moral solutions. Of course these developing capabilities would include the ability to talk which often, but not always, allows moral conflict to be efficiently resolved.

This view of morality gives importance to moral-emotional processes. Moral interchange surely evokes emotion that can give protagonists immediate, compelling, and accurate information about each other's sense of being violated or accepted as a moral equal. The present results suggest a second function: Emotional reactions may motivate partners' subsequent acts. There is no gainsaying but that "cool cognition" often-but not always-efficiently contributes to the refinement of solutions. Still the hallmark of actionable moral issues is hot cognition, laced with emotion.

These ideas are not inconsistent with several recent developments in behavioral science. Hoffman (1982), for example, suggests that the mimicry of affective empathy, as an unlearned response in infants, may be a precursor of morality. Charlesworth (1982) discusses ethological findings concerning affective communications in animals as unlearned social communications and points to their parallel in work with children. Zajonc $(1980,1984)$ maintains that emotion and cognition may be partially independent and that some emotional processes do not require cognitive mediation.

From the more distant fields of public policy and evolutionary biology, Axelrod and Hamilton (1981) describe the play of Prisoner's Dilemma among 78 computer programs (each matched with the others in five rounds of play), and reported that "the most successful" - in the sense of coming out ahead over some 400 plays-was a "nice" program that consistently attempted to equalize and did not immediately retaliate when violated. Instead this program "forgave" the other violating programs for a while. This is consistent with our finding that when the victim smiled after being violated, partners equalized in the next play, whereas negative expressions led to the children's intransigence and thus to their continued protection of self-interest. In a study of reciprocal restraint among tree swallows, Lombardo (1985), also a biologist, reports results that model the "most successful solution" described by Axelrod and Hamilton. These authors suggest the time has come for the development of a formal theory of reciprocity among unrelated members of lower species.

Emotional interchange is not within the purview of computers, nor is cognitive negotiation within the capability of tree swallows. Still all this recent work, along with the results from this study, suggests a different way of thinking about morality: Reciprocity may be necessary for all life-even coming to the minds of humans who program computers to play Prisoner's Dilemma. But social scientists' task is much more complicated because only humans have the possibilities to communicate both emotionally and cognitively as they attempt to achieve reciprocity.

\section{References}

Anderson, N. H. (1980). Information integration theory in developmental psychology. In F. Wilkening, J. Becker, \& T. Trabasso (Eds.), Information integration by children (pp. ). Hillsdale, $\mathrm{NJ}$ : Erlbaum.

Axelrod, R. (1984). The evolution of cooperation. New York: Basic Books.

Axelrod, R., \& Hamilton, W. D. (1981). The evolution of cooperation. Science, 211, 1390-1396.

Berndt, T. J. (1983). Social cognition, behavior, and children's friendships. In E. T. Higgins, D. N. Ruble, \& W. W. Hartup (Eds.), Social cognition and social development: $A$ sociacultural perspective (pp. 158-189). Cambridge: Cambridge University Press.

Charlesworth, W. (1982). An ethological approach to research on facial expressions. In C. E. Izard (Ed.), Measuring emotions in infants and children (pp. ). Cambridge: Cambridge University Press.

Cofer, C. N. (1981). The history of the concept of motivation. Journal of the History of the Behavioral Sciences, 17, 48-53.

Dawes, R. M., Orbell, J. M., \& Van de Kraft, J. C. (1985). Cooperation in the absence of incentive compatability. Manuscript submitted for publication.

Ekman, P., \& Friesen, W. V. (1975). Unmasking the face. Englewood Cliffs, NJ: Prentice-Hall.

Ekman, P. \& Friesen, W. V. (1978). Manual for the Facial Action Coding System. Palo Alto, CA: Consulting Psychologists Press.

Ekman, P., \& Friesen, W. V. (1982). Felt, false, and miserable smiles. Journal of Nonverbal Behavior, 6, 238-252.

Ekman, P., \& Friesen, W. V. (1983). Manual for the Emotion Facial Action Coding System (EMFACS). Unpublished manuscript.

Gottman, M. T., \& Parkhurst, J. T. (1980). A developmental theory of friendship and acquaintanceship processes. In W. A. Collins (Ed.), Minnesota Symposium on Child Psychology (Vol. 13, pp. 197-253). Hillsdale, NJ: Erlbaum.

Haan, N. (1978). Two moralities in action contexts. Journal of Personality and Social Psychology, 36, 286-305.

Haan, N. (in press). Systematic variability in the quality of moral action, as defined by two formulations. Journal of Personality and Social Psychology.

Haan, N., Aerts, E., \& Cooper, B. (1985). On moral grounds: Social scientists' search for practical morality. New York: New York University Press.

Hoffman, M. (1982). Affect and moral development. In D. Cichetti \& 
P. Hesse (Eds.), New directions for child development. San Francisco: Jossey-Bass.

Kruskal, J. W. (1964). Multidimensional scaling by optimizing goodness-of-fit to a non-metric hypothesis. Psychometrika, 29, 1-27.

Lombardo, M. P. (1985). Mutual restraint in tree swallows: A test for the tit-for-tat model of reciprocity. Science, 227, 1361-1363.

Main, M., \& George, C. (1985). Responses of abused and disadvantaged toddlers to distress in agemates: A study in the day care setting. Developmental Psychology, 21(3), 407-412.

Nelson, J., \& Aboud, F. E. (1985). The resolution of social conflict between friends. Child Development, 56, 1009-1017.

Newcomb, A. F., Brady, J. E., \& Hartup, W. W. (1979). Friendship and incentive condition as determinants of children's task-oriented social behavior. Child Development, 50, 878-881.

Newcomb, A., \& Brady, J. (1982). Mutuality in boy's friendship relations. Child Development, 53, 392-395.

Radke-Yarrow, M., Zahn-Waxler, C., \& Chapman, M. (1983). Children's prosocial dispositions and behavior. In P. H. Mussen (Ed.), Handbook of child psychology: Vol. IV. Socialization, personality and social development. New York: Wiley.
Rapoport, A., \& Chammah, A. (1965). Prisoner's dilemma. Ann Arbor: University of Michigan Press.

Rawls, J. (1971). The theory of justice. Cambridge, MA: Harvard University Press.

Rheingold, H. S., \& Hay, D. F. (1980). Prosocial behavior of the very young. In G. Stent (Ed.), Morality as a biological phenomenon (pp. ). Berkeley: University of California Press.

Siegal, M., \& Francis, R. (1982). Parent-child relations and cognitive approaches to the development of moral judgment and behavior. British Journal of Psychology, 73, 001-010.

Strayer, J. (1980). A naturalistic study of empathic behaviors and their relation to affective states and perspective-taking skills in preschool children. Child Development, 51, 815-822.

Zajonc, R. B. (1980). Feeling and thinking: Preferences need no inferences. American Psychologist, 35, 151-175.

Zajonc, R. B. (1984). On the primacy of affect. American Psychologist, $39,117-123$.

Received October 10, 1985

Revision received January 29, 1986 